\title{
Analiza gibanja oči med branjem pri bolnikih z različnimi stopnjami kognitiunega upada
}

Vida Groznik $1,2,3$, Aleksander Sadikov ${ }^{1,2}$

${ }^{1}$ NEUS Diagnostics, d.o.o., Ziherlova ulica 40E, 1000 Ljubljana

¿Univerza v Ljubljani, Fakulteta za računalništvo in informatiko, Večna pot 113, 1000 Ljubljana

${ }^{3}$ Univerza na Primorskem, Fakulteta za matematiko, naravoslovje in informacijske tehnologije, Glagoljaška 8, 6000 Koper

vida.groznik@fri.uni-lj.si, aleksander.sadikov@fri.uni-lj.si

\section{Izvleček}

S staranjem prebivalstva se močno povečuje število bolnikov z demenco, kar predstavlja vedno večji družbeni problem. Poleg samega bolnika z demenco, breme bolezni občutijo tudi njegovi bližnji. Blag kognitivni upad (MCI) je stanje kognitivnega funkcioniranja med tistim, ki ga opazimo pri običajnem staranju in tistim, ki ga zaznamo pri osebah z demenco. Raziskave kažejo, da okvirno $10 \%$ do $15 \%$ bolnikov z MCl v roku enega leta napreduje v Alzheimerjevo demenco. Obenem obstajajo indici, da je v zgodnji fazi kognitivnega upada razvoj bolezni velikokrat še možno zavreti; posledično je zgodnje odkrivanje kognitivnega upada precejšnjega pomena. Gibanje oči med branjem se je v zadnjih letih izkazalo kot eden izmed obetavnih bioloških označevalcev za zaznavanje kognitivnega upada. V pričujoči raziskavi smo analizirali gibanje oči med branjem pri 115 preiskovancih, ki so bili razdeljeni v štiri skupine glede na stopnjo kognitivnega upada; od povsem zdravih do preiskovancev z demenco. Njihov pogled smo posneli s sistemom za spremljanje očesnih gibov, posnetke pa smo opisali z lastnim naborom atributov. Analiza porazdelitev vrednosti atributov je pokazala, da se te značilno razlikujejo v odvisnosti od stopnje kognitivnega upada.

Ključne besede: blag kognitivni upad, demenca, branje, sledenje očesnih gibov

\section{Abstract}

With the aging of the population, the number of people suffering from dementia is on the rise. This represents an ever-growing problem for the society as the close relatives and caretakers of patients with dementia share the burden of the disease. Mild cognitive impairment (MCI) is a state of cognitive decline between normal aging and dementia. Recent studies estimate that between $10 \%$ and $15 \%$ of patients with $\mathrm{MCl}$ progress to dementia within a year. There are indications that the progression of the disease can often be slowed down during the early stage of the cognitive decline. Therefore, the early detection of the cognitive decline is highly desirable. Eye movement during reading has been shown to be a promising biomarker of $\mathrm{MCl}$. In this study, we analysed the eye movement of 115 participants during reading. The participants were grouped into four levels of cognitive decline; from healthy control to patients with dementia. Their eye movements were recorded with an eye-tracker and these recordings were described with our proposed set of descriptive attributes. The distributions of the attribute values were shown to be significantly different between various levels of cognitive decline.

Keywords: Mild cognitive impairment, dementia, reading, eye-tracking

\section{UVOD IN MOTIVACIJA}

Večkot 50 milijonov ljudi po celem svetu ima eno izmed oblik demence, kar bolezen uvršča na prvo mesto med vsemi nevrodegenerativnimi boleznimi. Zaradi staranja prebivalstva se predvideva, da bo konec tega desetletja število obolelih z demenco naraslo na 82 milijonov, leta 2050 pa bo to diagnozo imelo kar 152 milijonov ljudi [Alzheimer's Disease Internatio- nal, 2019]. Blag kognitivni upad (MCI) je stanje kognitivnega funkcioniranja med tistim, ki ga opazimo pri običajnem staranju in tistim, ki ga zaznamo pri osebah z demenco.

Za razliko od demence, pri osebah z MCI dejavnosti vsakdanjega življenja in kakovost življenja niso bistveno prizadeti. [Hugo and Ganguli, 2014]

Po ocenah pri nekje med 10 in $15 \%$ bolnikov z 
MCI bolezen v roku enega leta napreduje v Alzheimerjevo demenco (AD) [Farias et al., 2009]. Raziskave kažejo, da je moč $\mathrm{z}$ uporabo različnih pristopov zavreti ali celo preprečiti nastanek demence oz. MCI [Ayati et al., 2020]. Med te pristope sodijo različne terapije za nekatere druge bolezni, kot so različna nesteroidna protivnetna zdravila [Szekely et al., 2008] ter statini [Swiger et al., 2013], različne nefarmacevtske metode, kot na primer spremembe življenjskega sloga [Lourida et al., 2019], uživanje mediteranske prehrane [Lourida et al., 2013], zmanjšano uživanje al- kohola [Letenneur, 2004], fizična telesna aktivnost [Cass, 2017], ipd. Vse te ugotovitve so še dodatna motivacija za raziskovanje različnih bioloških označevalcev za zgodnje odkrivanje kognitivnega upada.

V zadnjih letih se je izkazalo, da je gibanje oči med branjem lahko eden izmed možnih bioloških označevalcev za detekcijo AD [Lueck et al., 2000] in tudi MCI [Fraser et al., 2017]. Razlog za to bi lahko bilo dejstvo, da je branje eno izmed bolj zahtevnih miselnih procesov, ki zahteva uporabo številnih kognitivnih sposobnosti kot so pozornost, kratkoročni in dolgoročni spomin, vidno in slušno procesiranje ter senzorika. Poleg tega so raziskave pokazale, da imajo bolniki z AD težave $z$ branjem zaradi primarnih okulomotornih nepravil- nosti kot je nestabilnost fiksacije [Lueck et al., 2000, Wilcockson et al., 2019]. Pri teh bolnikih se namreč postopoma razvije okvara nadzora inhibicije in popravljanja napak pri premikanju oči, predvsem sposobnost prostovoljnega usmerjanja pogleda stran od stimulusa pri testu antisakad (AST). Poleg tega pogostost napak pri izvajanju nalog AST korelira s stopnjo AD. [Wilcockson et al., 2019] Pomembna ugotovitev je tudi, da se težave z gibanjem oči lahko pojavijo že v zelo zgodnjih fazah razvoja bolezni, ko različnih kognitivnih primanjkljajev s standardnimi nevropsihološkimi testi še ni mogoče zaznati [Crawford et al., 2005].

Glavni namen pričujoče raziskave je ugotoviti, kako se izraža gibanje oči med branjem pri različnih stopnjah kognitivnega upada in posledično, če med skupinami obstajajo pomembne razlike. To bi v nadaljevanju lahko vodilo do avtomatiziranega testa za odkrivanje zgodnjega kognitivnega upada in stopnje le-tega na podlagi branja.

V nadaljevanju članka najprej povzamemo klinično raziskavo, postopek rekrutacije preiskovancev in metode, ki so bile uporabljene med izvajanjem raziskave. V tretjem poglavju orišemo strukturo preisko- vancev v tej analizi in atribute, ki smo jih predlagali za potrebe analize očesnih gibov med branjem. Rezultati raziskave so predstavljeni v poglavju štiri, čemur sledi diskusija rezultatov. Zaključki in nadaljnje delo so podani v sklepnem poglavju.

\section{KLINIČNA RAZISKAVA}

Podatki uporabljeni v pričujoči raziskavi so bili zbrani v okviru klinične raziskave, ki je bila odobrena s strani Komisije Republike Slovenije za medicinsko etiko (št. 0120-400/2015-5 in 0120-400/2015/9). Raziskava je potekala v skladu z dobro klinično prakso in nacionalnimi predpisi s čimer smo zagotovili zaščito pravic, varnost in dobro počutje preiskovancev $\mathrm{v}$ skladu z etičnimi načeli, ki izhajajo iz Helsinške deklaracije Svetovnega zdravniškega združenja [World Medical Association, 2013].

\subsection{Rekrutacija preiskovancev}

Vsi preiskovanci so k raziskavi pristopili prostovoljno. Informacijo o možnosti sodelovanja so prejeli na različne načine: s strani osebnih zdravnikov ali nevrologov po tem, ko so izrazili skrb, da imajo kognitivne težave (subjektivna kognitivna motnja), od raziskovalcev vključenih $\mathrm{v}$ raziskavo ali od predhodno vključenih preiskovancev.

$\mathrm{Ob}$ sami rekrutaciji smo upoštevali vključitvene in izključitvene kriterije. Osebe, vključene v raziskavo, so tako morale biti starejše od 40 let pri čemer niso smele imeti nekorigiranih vidnih napak, konkomitantnih nevroloških bolezni (izjema sta seveda blag kognitivni upad in demenca) ter niso smele zlorabljati mamil ali alkohola.

\subsection{Potek raziskave}

Pred vključitvijo v raziskavo je bil vsak preiskovanec pisno in ustno seznanjen $\mathrm{z}$ vsebino in namenom raziskave, predvidenim trajanjem raziskave in $\mathrm{z}$ njegovo pravico, da lahko kadarkoli odstopi od raziskave. Vsak preiskovanec je nato podpisal privolitev za sodelovanje $\mathrm{v}$ raziskavi.

Raziskava je potekala v treh sklopih:

\section{Nevrološki pregled}

Nevrološki pregled je zajemal ocenjevanje kognitivnega stanja preiskovancev in po potrebi še njihovega motoričnega in nemotoričnega stanja.

$S$ pomočjo vprašalnika smo preiskovance povprašali o demografskih podatkih in sicer o: letnici 
rojstva, ročnosti, izobrazbi, poklicu, datumu (morebitne) diagnoze, dolžini trajanja (morebitne) bolezni, trenutni terapiji, ostalih boleznih, morebitnih poškodbah glave in o družinski anamnezi.

Okviren čas trajanja: 15-20 minut

\section{Nevropsihološko testiranje}

Nevropsihološko testiranje je zajemalo oceno višjih kognitivnih sposobnosti, kot so izvršilne funkcije in spomin. Pri testiranju so bili uporabljeni naslednji standardizirani teti: Kognitivni preizkus Addenbrooke-KPA-R [Mioshi et al., 2006], Kratka baterija frontalnih testov - FAB (angl. Frontal Assessment Battery) [Slachevsky et al., 2004], CTMT (angl. Comprehensive Trail Making Test ) [Bowie and Harvey, 2006] in Geriatrična lestvica depresivnosti - 15 vprašanj (angl. Geria- tric Depression Scale - 15 questions) [Conradsson et al., 2013].

Okviren čas trajanja: 45-60 minut

\section{Testiranje očesnih gibov}

Testiranje očesnih gibov je bilo opravljeno z namensko programsko opremo NEUS slovenskega proizvajalca NEUS Diagnostics, d.o.o., ki je bil sponzor raziskave. Programska oprema je bila nameščena na prenosni računalnik, ki je imel priklopljen dodatni zaslon (z diagonalo velikosti $61 \mathrm{~cm}$ ) in napravo za sledenje očesnim gibom (angl. eye-tracker). Uporabili smo model naprave 4C švedskega proizvajalca Tobii $\mathrm{s}$ frekvenco zajema $90 \mathrm{~Hz}$. Preiskovanec je sedel približno $70 \mathrm{~cm}$ od zaslona in ni imel neposrednega stika z opremo. Interakcija preiskovanca s programom je potekala zgolj z njegovim pogledom na zaslon. Celoten postopek testiranja je izvedel in nadzoroval tehnik, ki je upravljal z računalnikom in programsko opremo. Navodila za posamezno nalogo so bila izpisana na računalniškem zaslonu in hkrati predvajana v zvočni obliki.

Preiskovancem smo vizualne dražljaje prikazali na računalniškem zaslonu $\mathrm{z}$ uporabo namenske programske opreme NEUS, ki jih je tudi vodila skozi vse naloge baterije testov. Programska oprema je podatke o gibanju oči, ki jih je beležila s pomočjo naprave za sledenje pogleda, shranila v podatkovno bazo. Vsi podatki so bili anonimizirani, dostop do podatkovne baze pa so imeli zgolj raziskovalci, ki so sodelovali v raziskavi.

Pred začetkom samega testiranja, je bilo potrebno izvesti kalibracijo sistema ločeno za vsakega preiskovanca. Po uspešni začetni kalibraciji so bili preiskovanci pozvani, da preberejo besedilo, ki je bilo prikazano na zaslonu. Besedilo je obsegalo 13 vrstic in je bilo razdeljeno v štiri odstavke. Ko je preiskovanec prebral celotno besedilo, je moral to eksplicitno potrditi s pogledom $\mathrm{v}$ spodnji desni kot zaslona, kjer je bila izrisana kljukica.

\section{Okviren čas trajanja: 25-30 minut}

Na podlagi nevrološkega pregleda in nevropsihološkega testiranja so preiskovanci prejeli eno izmed naslednjih diagnoz: $z$ drav (brez kognitivnega upada), mejno (zaznanih nekaj znakov kognitivnega upada a ne dovolj, da bi preiskovanca lahko diagnosticirali z blagim kognitivnim upadom), MCI (blag kognitivni upad) ali demenca.

\section{PODATKI}

\subsection{Preiskovanci}

Podatki, ki smo jih uporabili za to raziskavo, so vključevali 115 zaporedno vključenih preiskovancev starih med 43 in 94 let z mediano 68 let. Med njimi je bilo 85 preiskovank in 30 preiskovancev.

Zdravih preiskovancev je bilo 53, diagnozo mejno je imelo 32 preiskovancev, 19 preiskovancev je imelo MCI in 11 demenco. Podrobnejša porazdelitev preiskovancev po starosti in spolu glede na diagnozo/ skupino je prikazana v Tabeli 1.

\section{Tabela 1: Porazdelitev preiskovancev glede na spol in starost za posamezno skupino.}

\begin{tabular}{lcccc}
\hline & zdrav & mejno & MCI & demenca \\
\hline $\mathrm{N}$ & 53 & 32 & 19 & 11 \\
\hline Starostna porazdelitev & & & & \\
\hline Najnižja starost & 48 & 60 & 43 & 72 \\
\hline Najvišja starost & 83 & 87 & 91 & 94 \\
\hline Srednja starost & 63 & 68.5 & 72 & 83 \\
\hline Porazdelitev po spolu & & & & \\
\hline Ženska & 40 & 24 & 12 & 9 \\
\hline Moški & 13 & 8 & 7 & 2 \\
\hline
\end{tabular}

\subsection{Atributi za opis očesnih premikov med branjem}

Gibanje oči med branjem ni gladko, temveč tvori izmenično zaporedje sakad (angl. saccade) in fiksacij (angl. fixation). Sakade so hitri očesni premiki med dvema točkama, fiksacije pa krajše zaustavitve pogleda na neki točki. Upoštevaje frekvenco zajema podatkov, lastnosti zaslona in velikost besedila v našem konkretnem primeru, smo fiksacije definirali kot zaporedje 
posnetkov trajajoče najmanj 48ms, pri čemer največja razdalja poljubnih dveh posnetkov znotraj zaporedja ne presega 100 pikslov. Sakade smo izračunali kot premike med dvema zaporednima fiksacijama.

Predobdelava posnetkov branja je vključevala izločitev neveljavnih časovnih točk $\mathrm{v}$ posnetku; to so časovne točke, ko naprava za sledenje pogleda le-tega ni zaznala. Razlogi za to so lahko različni, najpogosteje gre za mežikanje $z$ očmi, lahko pa do tega pride tudi zaradi pogleda izven površine zaslona, nerodne pozicije glave ipd. Poleg tega smo odstranili začetnih $5 \%$ in končnih $10 \%$ posnetka. Na teh mestih zna biti obnašanje preiskovanca nepovezano s samim branjem.

Branje oziroma gibanje pogleda med branjem smo opisali z naborom atributov, ki smo jih $\mathrm{v}$ ta namen definirali. Pri tem smo zasledovali cilj, da poskušamo zajeti kar se da veliko pomembnih značilnosti branja s čim manjšim naborom atributov za kasnejšo uporabo v strojnem učenju. Pri zasnovi atributov smo se opirali na izkušnje iz lastne pilotne raziskave ter na domensko znanje, ki smo ga pridobili od nevrologov in psihologov. Atribute smo definirali na podlagi predhodno zaznanih sakad in fiksacij. Podrobneje so opisani v nadaljevanju.

Dolžina sakad v smeri naprej (fdist) in v smeri nazaj (bdist) je definirana kot srednja dolžina sakad v ustrezni smeri (naprej oziroma nazaj). Smer sakade je razvidna iz zaslonskih koordinat fiksacije pred in po izvedeni sakadi. Oba atributa sta povezana s hitrostjo branja, vsebujeta pa tudi druge zanimive informacije. Dolžina sakad nazaj je na primer neposredno povezana s skoki v novo vrstico besedila ter tudi morebitnim ponovnim branjem določenih besed.

Razpršenost dolžin sakad nazaj (bdist.stdev) se izračuna kot standardni odklon dolžin vseh zaznanih sakad v smeri nazaj. Kot že omenjeno, ta atribut je tesno povezan s skokom v novo vrstico besedila. Večinoma gre zato tukaj za precej dolge sakade, dolge približno toliko kolikor je dolga vrstica teksta. Visoka vrednost tega atributa, torej velika razpršenost dolžin sakad, bi lahko sporočala, da uporabnik poleg skokov v novo vrstico dela tudi precej krajših sakad nazaj, morda zato, ker ponovno prebira določene besede ali ker se je v besedilu izgubil.

Razpršenosti dolžin sakad naprej nismo uporabili kot atribut, ker ne izhaja iz domenskega znanja, kot razpršenost dolžin sakad nazaj. Slednji je zanimiv zaradi morebitne mešanice dolgih skokov v novo vr- stico in kratkih pomikov pogleda nazaj, ki so odraz ponovnega branja ene ali več predhodnih besed. Pri branju naprej daljši skoki v smeri branja niso prisotni in bi bil atribut posledično odveč.

Hitrost sakad v smeri naprej (fspeed) in sakad v smeri nazaj (bspeed) je definirana kot srednja hitrost sakad v ustrezni smeri. Kljub temu, da sta dolžina in hitrost sakad do neke mere korelirani med seboj, smo že v pilotni raziskavi opazili, da vsaka doprinese dodatne informacije o gibanju pogleda med branjem.

Trajanje fiksacije (fdur) izračunamo kot srednjo vrednost trajanja vseh zaznanih fiksacij, razpršenost trajanja fiksacij (fdur.std) pa kot standardni odklon trajanj fiksacij. Oba atributa lahko povežemo z nekonsistentim in zmedenim obnašanjem med branjem.

Razmerje med sakadami naprej in nazaj $\left(f_{s} V\right.$ bs) izračunamo kot število sakad naprej deljeno s številom sakad nazaj. Število fiksacij na časovno enoto (fxt) pa izračunamo kot število vseh zaznanih fiksacij deljeno s trajanjem posnetka. Ta atribut predstavlja bolj robustno mero za hitrost branja.

\section{REZULTATI}

$\mathrm{V}$ raziskavi nas je predvsem zanimalo, če (1) preiskovanci z različno stopnjo kognitivnega upada izkazujejo različne značilnosti gibanja pogleda med branjem in (2) če naši atributi uspejo te razlike zaznati. S tem namenom smo primerjali porazdelitve vrednosti posameznih atributov med vsemi štirimi skupinami preiskovancev.

Porazdelitve vrednosti atributov večinoma ne sledijo normalni porazdelitvi, zato smo za njihovo primerjavo uporabili neparametrični Kruskal-Wallisov $\mathrm{H}$ test. Rezultati so zbrani v Tabeli 2. Poleg statistične značilnosti (p-vrednosti) so v tabeli navedene še nekatere druge lastnosti porazdelitev vrednosti.

Statistične značilnosti nakazujejo, da so med skupinami preiskovancev (velike) razlike $\mathrm{v}$ porazdelitvah predlaganih atributov. $\mathrm{Z}$ izjemo atributa bdist. $s t d$, ki je dokaj mejno statistično značilen, so vsi preostali močno statistično značilni. Vendar pa je Kruskal-Wallisov $\mathrm{H}$ test omnibus test, torej sporoča, če je katera od skupin značilno drugačna od katerekoli druge skupine $\mathrm{v}$ porazdelitvi atributa. Namesto naknadnih dodatnih primerjav med posameznimi skupinami smo porazdelitve vrednosti predstavili raje grafično na Sliki 1 . Na sliki so prikazani histogrami za vse atribute po vseh skupinah. Poleg tega so gostote porazdelitev vrednosti atributov po skupinah 
ocenjene z jedri (angl. kernel density estimation) in prikazane s krivuljami na histogramih.

Iz grafov na Sliki 1 lahko razberemo, da vsi atributi (z izjemo bdist.std) izkazujejo različne porazdelitve med skupinami, predvsem med skupinama zdravih preiskovancev in preiskovancev z demenco. Nadalje je iz grafov razvidno tudi, da skupine izkazujejo urejenost po stopnji kognitivnega upada, od zdravih preko mejnih in preiskovancev z blagim kognitivnim upadom pa do preiskovancev $\mathrm{z}$ demenco.

Tabela 2: Porazdelitev urednosti atributov sledenja očesnim gibom po skupinah preiskovancev (zdrav, mejno, MCI, demenca).

\begin{tabular}{|c|c|c|c|c|c|c|}
\hline Atribut & p-vrednost & Skupina & Mediana & Stand. dev. & Minimum & Maksimum \\
\hline & & zdrav & -45.91 & 15.86 & -52.23 & -8.75 \\
\hline bdist & $<0.001$ & mejno & -37.56 & 15.85 & -65.59 & -8.11 \\
\hline \multirow[t]{3}{*}{ [\% zaslona] } & & $\mathrm{MCl}$ & -16.95 & 16.10 & -47.77 & -7.48 \\
\hline & & demenca & -13.16 & 4.45 & -20.52 & -7.81 \\
\hline & & zdrav & 18.15 & 3.01 & 7.79 & 22.45 \\
\hline bdist.std & 0.036 & mejno & 18.62 & 2.01 & 14.12 & २2.26 \\
\hline \multirow[t]{3}{*}{ [\% zaslona] } & & $\mathrm{MCl}$ & 19.89 & 3.86 & 8.51 & 25.95 \\
\hline & & demenca & 16.49 & 3.80 & 8.34 & 21.10 \\
\hline & & zdrav & -4.30 & 1.70 & -8.37 & -0.37 \\
\hline bspeed & $<0.001$ & mejno & -4.36 & 1.31 & -7.44 & -1.35 \\
\hline \multirow[t]{3}{*}{ [piksel/ms] } & & $\mathrm{MCl}$ & -3.63 & 1.36 & -6.10 & -0.94 \\
\hline & & demenca & -2.74 & 0.89 & -4.45 & -0.92 \\
\hline & & zdrav & 7.74 & 1.01 & 6.43 & 11.48 \\
\hline fdist & 0.003 & mejno & 7.40 & 1.10 & 5.90 & 10.46 \\
\hline \multirow[t]{3}{*}{ [\% zaslona] } & & $\mathrm{MCl}$ & 7.55 & 1.13 & 6.08 & 9.86 \\
\hline & & demenca & 6.85 & 0.70 & 5.72 & 7.80 \\
\hline & & zdrav & 216.51 & 41.87 & 127.69 & 366.41 \\
\hline fdur & 0.001 & mejno & 244.29 & 58.06 & 111.03 & 421.92 \\
\hline \multirow[t]{3}{*}{ [ms] } & & $\mathrm{MCl}$ & 249.82 & 72.71 & 111.03 & 377.51 \\
\hline & & demenca & 294.31 & 92.76 & 144.34 & 410.82 \\
\hline & & zdrav & 111.48 & 33.91 & 42.51 & 220.09 \\
\hline fdur.std & $<0.001$ & mejno & 152.53 & 48.64 & 86.38 & 270.36 \\
\hline \multirow[t]{3}{*}{ [ms] } & & $\mathrm{MCl}$ & 148.25 & 75.53 & 92.66 & 400.54 \\
\hline & & demenca & २26.२० & 37.39 & 156.10 & 286.56 \\
\hline & & zdrav & 4.43 & 1.26 & 1.93 & 6.30 \\
\hline fsVbs & 0.003 & mejno & 4.03 & 1.12 & 2.10 & 6.57 \\
\hline \multirow[t]{3}{*}{ [brez enote] } & & $\mathrm{MCl}$ & 3.55 & 0.87 & 2.20 & 5.21 \\
\hline & & demenca & 2.88 & 0.74 & 1.94 & 4.57 \\
\hline & & zdrav & 3.17 & 0.61 & 0.23 & 3.99 \\
\hline fspeed & $<0.001$ & mejno & 3.07 & 0.74 & 0.68 & 4.00 \\
\hline \multirow[t]{3}{*}{ [piksel/ms] } & & $\mathrm{MCl}$ & 2.85 & 0.79 & 0.80 & 3.80 \\
\hline & & demenca & 2.65 & 0.66 & 0.64 & 3.03 \\
\hline & & zdrav & 3.28 & 0.67 & 0.71 & 4.80 \\
\hline fxt & $<0.001$ & mejno & 2.76 & 0.49 & 1.86 & 3.82 \\
\hline \multirow[t]{2}{*}{ [\#fiksacij/s] } & & $\mathrm{MCl}$ & 2.57 & 0.40 & 2.01 & 3.63 \\
\hline & & demenca & 2.04 & 0.34 & 1.59 & 2.82 \\
\hline
\end{tabular}




\section{RAZPRAVA}

V pričujočo študijo je bilo vključenih 115 preiskovancev. Vsi preiskovanci so opravili precej izčrpen nabor nevropsiholoških preiskav pri specialistu nevrologu in psihologu, na podlagi česar so bili razvrščeni v ustrezno skupino glede na stopnjo (morebitnega) kognitivnega upada. Na ta način je študija dobro pokrita tako z vidika velikosti vzorca kot tudi z vidika kvalitete podatkov.

Študija je pokazala, da obstajajo precejšnje razlike v gibanju pogleda med branjem pri preiskovancih z različno stopnjo kognitivnega upada. Prav tako je tudi razvidno, da so te razlike sposobni sistematično zaznati predlagani atributi za opis značilnosti gibanja pogleda med branjem. Tu velja posebej poudariti urejenost skupin kot jo prikazujejo porazdelitve vrednosti posameznih atributov. Le-ta ustreza nevrološkim in psihološkim pričakovanjem, da je kognitivni upad pravzaprav kontinuum, ki se počasi stopnjuje; od mejnega preko blagega kognitivnega upada pa vse do demence. To se tudi ujema z izsledki raziskav, ki predvidevajo, da relativno velik delež bolnikov z MCI v nekaj letih razvije različne oblike demence (npr. [Alexopoulos et al., 2006, Farias et al., 2009, Glynn et al., 2021]).

Iz porazdelitev vrednosti atributov na Sliki 1 je možno razbrati, da imajo preiskovanci $\mathrm{z}$ večjo stopnjo kognitivnega upada vse nižje število fiksacij na časovno enoto, njihove fiksacije so tipično vse daljše in predvsem vse bolj razpršenih trajanj (mešanica kratkih in dolgih fiksacij), hitrost njihovih sakad je vse počasnejša in dolžina sakad vse krajša (predvsem sakad v smeri nazaj). Tudi te ugotovitve se skladajo s pričakovanji.

Branje je vseprisotna človeška aktivnost. Kot tako je zelo naravno in primerno za poljubnega preisko-
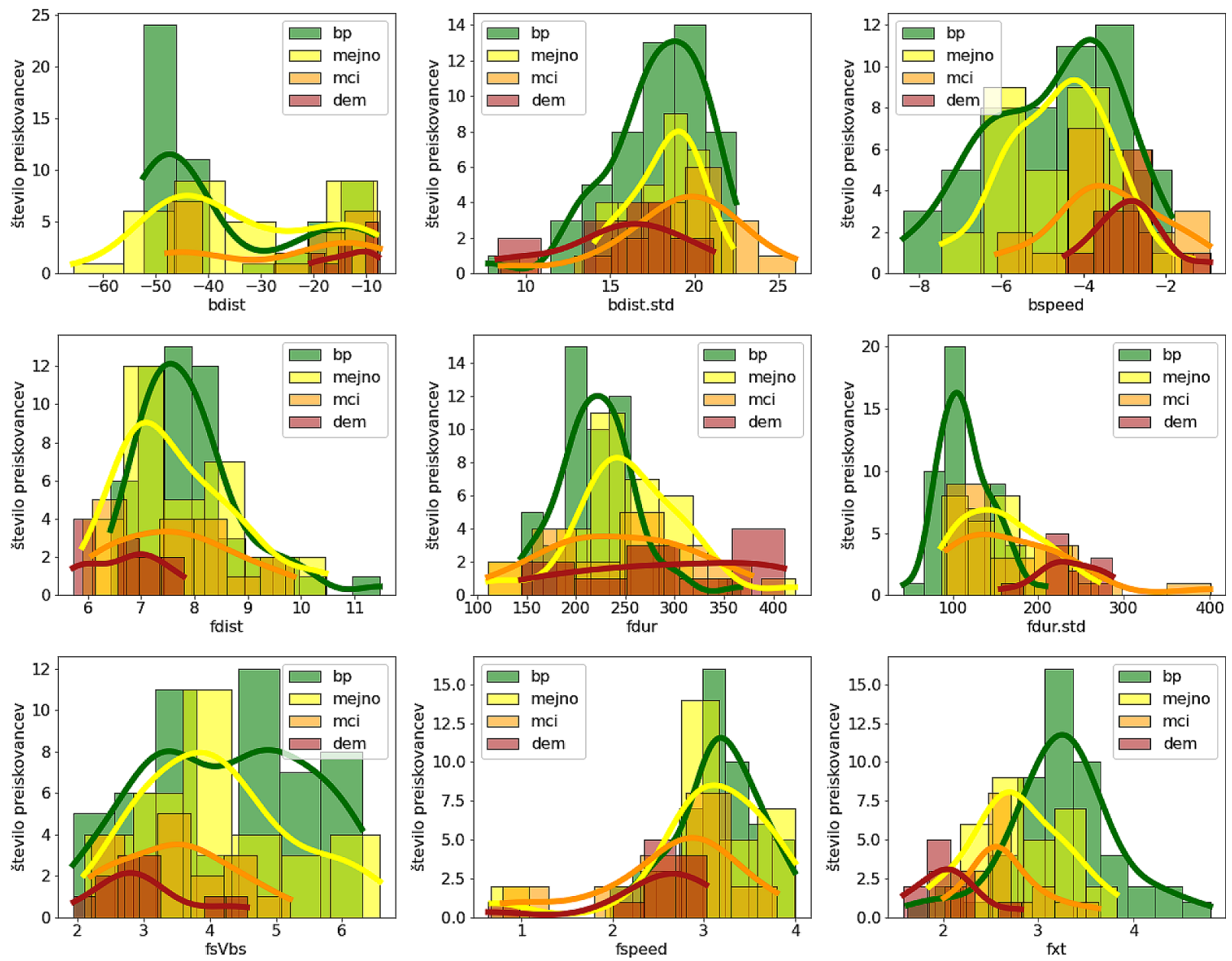

Slika 1: Porazdelitue urednosti atributou po posameznih skupinah. Na grafih so prikazani histogrami in krivulje, ki predstauljajo oceno gostote porazdelitve $\mathbf{z}$ jedri. 
vanca, še posebej glede na to, da gre za kratko besedilo s precej veliko pisavo. Naprava za spremljanje pogleda je prav tako nemoteča, marsikareri preiskovanec tanke podolgovate ploščice pod zaslonom niti zares ne opazi. $S$ tega vidika so dobljeni rezultati verjetno zelo realistični (gre res za značilnosti pogleda med branjem) in niso posledica npr. boljše sposobnosti prilagajanja preiskovanca na situacijo (angl. ecological validity).

\section{ZAKLJUČKI IN NADALJNJE DELO}

Na podlagi pričujoče raziskave lahko zaključimo, da obstajajo precejšnje razlike pri branju med osebami z različnimi stopnjami kognitivnega upada. Nadalje lahko potrdimo, da je te razlike možno zaznati preko predlaganih atributov s pomočjo naprav za spremljanje očesnih gibov. Prav tako se je pokazalo, da je kognitivni upad kontinuum. Faza "mejno", ki klinično še ne izkazuje zadostnih znakov za diagnozo blagega kognitivnega upada, se vendarle razlikuje od zdravega stanja. To je koristen podatek, ker nakazuje, da lahko kognitivni upad $\mathrm{v}$ določenih primerih zaznamo v še bolj zgodnji fazi.

Pomen odkritih razlik oziroma dejstva, da je s pomočjo predlaganega nabora atributov in spremljanja pogleda med branjem moč zaznati (blag) kognitivni upad, je v možnosti avtomatizacije tega postopka. Nadaljnje delo bo usmerjeno predvsem $\mathrm{v}$ uporabo predlaganih atributov $\mathrm{v}$ postopku izdelave napovednega modela prisotnosti znakov kognitivnega upada s pomočjo strojnega učenja ter njegove evalvacije. Poleg tega načrtujemo izdelavo baterije testov, ki bi vključevala branje, ter nekatere druge nevropsihološke teste, prilagojene za delovanje s sistemi za spremljanje očesnih gibov, kot je na primer naloga s Corsijevimi kockami [Groznik, 2020].

\section{ZAHVALA}

Raziskava je potekala v okviru projekta NEUS, ki je bil financiran s strani Evropskega inštituta za inovacije in tehnologijo - skupnost za inovacije znanja "Zdravje" (European Institute of Innovation and Technology (EIT) Health KIC). To telo Evropske Unije prejema podporo $\mathrm{v}$ okviru raziskovalnega in inovacijskega programa Horizon 2020.

\section{LITERATURA}

[1] [Alexopoulos et al., 2006] Alexopoulos, P., Grimmer, T., Perneczky, R., Domes, G., and Kurz, A. (2006). Progression to dementia in clinical subtypes of mild cognitive impairment. Dementia and geriatric cognitive disorders, 22(1):27-34.

[2] [Alzheimer's Disease International, 2019] Alzheimer's Disease International, L. (2019). World Alzheimer Report 2019: Attitudes to dementia. Alzheimer's Disease International (ADI).

[3] [Ayati et al., 2020] Ayati, Z., Chang, D., and Lake, J. (2020). Advances in treatment of mild cognitive impairment (mci) and dementia: A review of promising non-pharmaceutical modalities. Frontiers in Clinical Drug Research-Dementia: Volume 1, $1: 78$.

[4] [Bowie and Harvey, 2006] Bowie, C. R. and Harvey, P. D. (2006). Administration and interpretation of the Trail Making Test. Nature protocols, 1(5):2277.

[5] [Cass, 2017] Cass, S. P. (2017). Alzheimer's disease and exercise: a literature review. Current sports medicine reports, 16(1):19-22.

[6] [Conradsson et al., 2013] Conradsson, M., Rosendahl, E., Littbrand, H., Gustafson, Y., Olofsson, B., and Lövheim, H. (2013). Usefulness of the Geriatric Depression Scale 15-item version among very old people with and without cognitive impairment. Aging \& mental health, 17(5):638-645.

[7] [Crawford et al., 2005] Crawford, T. J., Higham, S., Renvoize, T., Patel, J., Dale, M., Suriya, A., and Tetley, S. (2005). Inhibitory control of saccadic eye movements and cognitive impairment in Alzheimer's disease. Biological Psychiatry, 57(9):1052 - 1060.

[8] [Farias et al., 2009] Farias, S. T., Mungas, D., Reed, B. R., Harvey, D., and DeCarli, C. (2009). Progression of mild cognitive impairment to dementia in clinic- vs community-based cohorts. Archives of neurology, 66(9):1151-1157.

[1] [Fraser et al., 2017] Fraser, K. C., Fors, K. L., Kokkinakis, D., and Nordlund, A. (2017). An analysis of eye-movements during reading for the detection of mild cognitive impairment. In Proceedings of the 2017 Conference on Empirical Methods in Natural Language Processing, pages 1016-1026.

[9] [Glynn et al., 2021] Glynn, K., O'Callaghan, M., Hannigan, O., Bruce, I., Gibb, M., Coen, R., Green, E., A Lawlor, B., and Robinson, D. (2021). Clinical utility of mild cognitive impairment subtypes and number of impaired cognitive domains at predicting progression to dementia: A 20-year retrospective study. International Journal of Geriatric Psychiatry, 36(1):31-37.

[10] [Groznik, 2020] Groznik, V. (2020). Digitalizacija in prilagoditev psihološkega testa za uporabo s sistemom za spremljanje očesnih gibov. Uporabna informatika, 28(4).

[11] [Hugo and Ganguli, 2014] Hugo, J. and Ganguli, M. (2014). Dementia and cognitive impairment: epidemio- logy, diagnosis, and treatment. Clinics in geriatric medicine, 30(3):421442.

[12] [Letenneur, 2004] Letenneur, L. (2004). Risk of dementia and alcohol and wine consumption: a review of recent results. Biological research, 37(2):189-193.

[13] [Lourida et al., 2019] Lourida, I., Hannon, E., Littlejohns, T. J., Langa, K. M., Hyppönen, E., Kuz'ma, E., and Llewellyn, D. J. (2019). Association of lifestyle and genetic risk with incidence of dementia. Jama, 322(5):430-437.

[14] [Lourida et al., 2013] Lourida, I., Soni, M., Thompson-Coon, J., Purandare, N., Lang, I. A., Ukoumunne, O. C., and Llewellyn, D. J. (2013). Mediterranean diet, cognitive function, and dementia: a systematic review. Epidemiology, pages 479-489.

[15] [Lueck et al., 2000] Lueck, K. L., Mendez, M. F., and Perryman, K. M. (2000). Eye movement abnormalities during reading in patients with Alzheimer disease. Neuropsychiatry, Neuropsychology, \& Behavioral Neurology. 
[16] [Mioshi et al., 2006] Mioshi, E., Dawson, K., Mitchell, J., Arnold, R., and Hodges, J. R. (2006). The Adden- brooke's Cognitive Examination Revised (ACE-R): a brief cognitive test battery for dementia screening. International Journal of Geriatric Psychiatry: A journal of the psychiatry of late life and allied sciences, 21(11):1078-1085.

[17] [Slachevsky et al., 2004] Slachevsky, A., Villalpando, J. M., Sarazin, M., Hahn-Barma, V., Pillon, B., and Dubois, B. (2004). Frontal assessment battery and differential diagnosis of frontotemporal dementia and Alzheimer disease. Archives of neurology, 61(7):1104-1107.

[18] [Swiger et al., 2013] Swiger, K. J., Manalac, R. J., Blumenthal, R. S., Blaha, M. J., and Martin, S. S. (2013). Statins and cognition: a systematic review and meta-analysis of short-and long-term cognitive effects. In Mayo clinic proceedings, volume 88, pages 1213-1221. Elsevier.
[19] [Szekely et al., 2008] Szekely, C. A., Breitner, J. C., Fitzpatrick, A. L., Rea, T. D., Psaty, B. M., Kuller, L. H., and Zandi, P. P. (2008). Nsaid use and dementia risk in the cardiovascular health study*: Role of apoe and nsaid type. Neurology, 70(1):17-24.

[20] [Wilcockson et al., 2019] Wilcockson, T. D., Mardanbegi, D., Xia, B., Taylor, S., Sawyer, P., Gellersen, H. W., Leroi, I., Killick, R., and Crawford, T. J. (2019). Abnormalities of saccadic eye movements in dementia due to Alzheimer's disease and mild cognitive impairment. Aging (Albany NY), 11(15):5389.

[21] [World Medical Association, 2013] World Medical Association (2013). World Medical Association Declara- tion of Helsinki: Ethical Principles for Medical Research Involving Human Subjects. JAMA, 310(20):2191-2194.

Vida Groznik je soustanoviteljica in direktorica podjetja NEUS Diagnostics, d.o.o. v okviru katerega razvijajo sisteme za pomoč pri oceni zdravstvenega stanja uporabnikov s pomočjo metod umetne inteligence. Poleg tega je docentka na Fakulteti za matematiko, naravoslovje in informacijske tehnologije na Univerzi na Primorskem ter raziskovalka v Laboratoriju za umetno inteligenco na Fakulteti za računalništvo in informatiko Univerze v Ljubljani. Doktorirala je leta 2018 z delom, ki je tesno povezovalo umetno inteligenco in nevrologijo. Je (so)avtorica več raziskovalnih člankov in poglavij v knjigah s področja umetne inteligence v medicini. Pridobila in delala je na različnih projektih financiranih s programov EU, Ministrstva za izobraževanje, znanost in šport ter Slovenskega podjetniškega sklada.

Aleksander Sadikov je docent in predstojnik Laboratorija za umetno inteligenco na Fakulteti za računalništvo in informatiko Univerze v Ljubljani. Vodil je oz. vodi več evropskih in domačih projektov, ki so povezani z uporabo umetne inteligence v medicini. Na tem področju ima tudi precejšnje število objav v znanstvenih revijah in konferencah. Poleg tega je soustanovitelj podjetja NEUS Diagnostics, d.o.o., ki razvija sisteme za oceno zdravstvenega stanja uporabnikov s pomočjo metod umetne inteligence. 